ARTÍCULO ORIGINAL

\title{
Empleabilidad de personas con discapacidad desde el marco rector de SENADIS, Paraguay
}

\author{
Employability of Persons with Disabilities from the Governance Framework of the \\ SENADIS, Paraguay
}

\section{Armin Reyes Giménez ${ }^{1}$}

Resumen: Con el objetivo de identificar la situación laboral de las Personas con Discapacidad $(P c D)$ en Paraguay, verificar el cumplimiento de las leyes de inserción laboral en instituciones públicas registradas en la Secretaria de la Función Pública e indagar sobre la inserción laboral de las Instituciones Privadas, en cuanto a la incorporación de PcD como empleados, se realiza el estudio observacional descriptivo de corte transversal, con enfoque cuali-cuantitativo. En la identificación de la situación laboral de las PcD en Paraguay, se observa que el pais cuenta con 316.324 PcD en edad económicamente activa, de las cuales 15.816 PcD están en condiciones de ser insertadas laboralmente. De esta población apenas el 1\% han logrado ser insertada. La población de PcD que solicitan empleo es uniforme en cuanto al sexo; tienen edad entre 26 y 35 años, nivel de estudio en su mayoría con secundaria incompleta; tienen preparación en informática, trabajo manual, administrativo, técnico, área de salud y arte. Sobre el tipo de discapacidad el mayor porcentaje tiene discapacidad física, seguida de la sensorial $e$ intelectual. En relación a las leyes, el pais cuenta con acciones positivas a favor de las PcD, aunque su aplicación es aún baja. En cuanto a la apertura de las Instituciones Privadas se observa que un número limitado de los PcD están insertos laboralmente a través de la responsabilidad social de las empresas.

Palabras clave: Empleabilidad; Personas con Discapacidad; Plan de Empleabilidad; SENADIS.

Abstract: In order to identify the employment status of persons with disabilities (PWDs) in Paraguay, verify compliance with employment laws in public institutions registered with the Ministry of Public Administration and investigate the opening of private institutions, as the inclusion of PWDs as employees, descriptive cross-sectional observational study, with qualitative and quantitative approach is performed. In identifying the employment situation of PWDs in Paraguay, it shows that the country has 316,324 PWD economically active age, of which 15,816 PWD are able to be inserted in work. Of this population only 1\% have managed to be inserted. PWD population seeking employment is even about sex; with age between 26 and 35, level of study mostly with incomplete secondary; they have training in computer, manual labor, administrative, technical, health and art area. On the type of disability has the highest percentage physical disability, followed by sensory and intellectual. In relation to laws, the country has positive actions in favor of PWDs, although implementation is still low. As for the opening of private institutions it shows that a limited number of PWDs are embedded occupationally through the social responsibility of companies.

Keywords: Employability; People with disabilities; Employability Plan; SENADIS.

\footnotetext{
1 Analista de Sistemas, Máster en Ciencias de la Educación, Profesor en la Universidad Autónoma de Asunción (UAA), Paraguay. E-mail: (girear@hotmail.com). Este trabajo se inserta dentro del Plan de Discapacidad de la SENADIS (Secretaria Nacional por los Derechos Humanos de las Personas con Discapacidad). UAA, 2014, CDD: 371.9.
}

Recibido: 20/03/2015; Aceptado: 14/08/2015. http://dx.doi.org/10.18004/riics.2015.diciembre.209-222 


\section{INTRODUCCIÓN}

El termino discapacidad definida según la Clasificación Internacional de Deficiencias, Discapacidades y Minusvalías es toda "restricción o ausencia (debida a una deficiencia) de la capacidad de realizar una actividad en la forma o dentro del margen que se considera normal para un ser humano" (OMS, OPS, IMSERSO, 2004, p. 10). En los últimos tiempos, la definición de este término ha evolucionado considerándose como resultante de la "interacción entre las Personas con Discapacidad (PcD) y la sociedad", por lo tanto, la discapacidad consiste en las barreras físicas y actitudinales que impiden la participación plena y efectiva en igualdad de condiciones con los demás (OMS, 2012).

En Paraguay, la Constitución Nacional en su en su artículo 58 garantiza a todos sus habitantes un trabajo licito, libremente escogido y a realizarse en condiciones dignas y justas, sin embargo aquellas que tienen algún tipo de discapacidad, no gozan de estas garantías y tropiezan con dificultades para lograr oportunidades de un empleo adecuado en empresas, sean estas públicas o privadas. Así mismo, en el Capítulo VIII del Derecho Laboral en el artículo 88 de la no discriminación, hace referencia a que no se admitirá discriminación alguna entre los trabajadores por motivos étnicos, de sexo, de edad, religión, condición social y preferencias políticas o sindicales, garantiza además, que el trabajo de las personas con limitaciones o incapacidades físicas o mentales serán especialmente amparado (Constitución Nacional, 1992).

El Estado Paraguayo al ratificar e incorporar los convenios y tratados internacionales se compromete con el sector de la discapacidad, es así que el sector no se encuentra desvinculada de las leyes del país. Pero aun con la existencia de las leyes que las amparan, las PcD no están protegidas y persiste el desconocimiento de las leyes, principalmente, lo referente a la inclusión laboral en el sector público; se señalan la discriminación y la violación de los derechos de las PcD al no ser reconocidos en sus derechos ciudadanos por la precariedad de la inserción laboral. Cabe mencionar, que la ley de inserción laboral actual cuenta con una limitación al no ser extensiva al sector privado, que podría ser una alternativa de solución importante para el sector (Carrizosa, 2010).

Cada habitante del país contribuye al desarrollo del mismo; por medio de las politicas se crean las condiciones propicias en donde debe surgir las oportunidades para que todos seamos sujetos activos para la economía mediante el trabajo. La exclusión de las PcD de la inserción en un trabajo que lo dignifique como persona y 
ciudadanos, ocasiona consecuencias como el alto nivel de pobreza, asistencialismo, no acceso a la salud, la educación y el desempleo. Las PcD necesitan ser insertados en el área laboral, a fin de alcanzar paulatinamente su derecho a la igualdad de condiciones que las demás personas.

En el libro Mirando a las PcD desde una visión de derechos, Arregui y Romero (2010) nos indican que la equiparación de oportunidades se da por medio de los apoyos y ayudas técnicas a lo largo de la vida laboral de la persona, para posibilitar el mantenimiento del puesto y del rendimiento requerido. En este sentido, Paraguay necesita implementar una política de Estado que cree un mecanismo de control del acatamiento de la ley de inserción laboral, que regule las condiciones de trabajo de las $\mathrm{PcD}$, que se incentive el acceso al trabajo y que fortalezca la participación de las PcD en la búsqueda del cumplimiento efectivo de sus derechos.

En el país, el Instituto Nacional de Personas Excepcionales (INPRO) es una Institución del Estado que brinda servicios de atención a los temas relacionados a la discapacidad, fue creado por la ley 780/79 y que en octubre del año 2012 se convierte en Secretaria Nacional por los Derechos de las Personas con Discapacidad (SENADIS) (Ley 780/79, 1979; Ley 4720/12, 2012).

La SENADIS, es el ente rector que vela por los Derechos Humanos de las Personas con Discapacidad. Tiene como misión garantizar la igualdad de oportunidades, la inclusión social, el respeto de los derechos a la participación en el dialogo nacional, con miras a mejorar su calidad de vida siendo útil a sí mismo, a la familia y la sociedad (Ley 4720/12, 2012). Es de interés de la SENADIS apoyar investigaciones que ayuden a cumplir con los compromisos internacionales contraídos con el programa del decenio de la Organización de los Estados Americanos (OEA) y la Convención sobre los derechos de las PcD de la Organización de las Naciones Unidas (ONU), además de ordenar y manejar las problemáticas de la discapacidad en el área laboral y así como impulsar la generación de políticas nacionales (SENADIS, 2014).

Considerando que el tema de la inclusión, en el país, requiere una ruptura en los sistemas, que la sociedad se adapte para atender a las necesidades de las PcD, valorizar la individualidad, adaptación a las realidades de los modelos que ya existen y defender los derechos de las PcD; en el presente estudio se aborda la empleabilidad de las personas con discapacidad desde el marco rector de la Secretaria Nacional por los Derechos Humanos de las Personas con Discapacidad 
con el objetivo de identificar la situación de las PcD en actividad laboral en el ámbito público, verificar el cumplimiento de las leyes de inserción laboral en instituciones públicas registradas en la Secretaria de la Función Pública e indagar sobre la inserción laboral de las $\mathrm{PcD}$ en las instituciones privadas, en cuanto a la incorporación de PcD como empleados.

Se pretende obtener un conocimiento de la situación real y actual de la problemática para aportar un diseño actualizado del Plan Nacional de Discapacidad, que constituya un modelo a ser utilizado como articulador de la Política de Empleo de las PcD tanto en el ámbito público y privado; que ejecute un plan social estratégico de acciones dentro de las políticas públicas.

\section{METODOLOGÍA}

Estudio observacional descriptivo de corte transversal, con enfoque cualicuantitativo realizado durante el año 2014. Para identificar a la población de Personas con discapacidad ( $\mathrm{PcD}$ ) se consultó como fuente de información la Estadística de Encuestas y Censos de la Dirección General de Estadística, Encuestas y Censos (DGEEC, 2009). Para determinar la población de PcD económicamente activa se utilizó el parámetro del 10\% de la OMS (2009) y para identificar a la población de PcD económicamente activa que demanda empleo en el país, se recurrió a la base datos de la SENADIS del Departamento de Inserción Laboral, previa autorización se procedió a examinar las carpetas presentadas por los usuarios que contiene el curriculum vitae, certificado de discapacidad, test psicolaboral expedida por la SENADIS y la carta de pedido de empleo dirigida a la Instituciones públicas o privadas. Los datos se transcribieron en una planilla Excel, se codificó, se tabuló y luego se procedió a representar en forma gráfica. La muestra fue conformada por 85 usuarios que se postularon para la obtención de empleo.

La recolección de datos relacionados a la población de Personas con Discapacidad insertadas en el ámbito laboral público y el cumplimiento de la Ley 3585/08 se realizó a través de visita a la Secretaría de la Función Pública (SFP), secretaría encargada del cumplimiento de la ley; en donde se conversó con la Directora de Derechos Humanos, Igualdad e Inclusión, quien proporcionó la información de las instituciones públicas registradas con la cantidad total de funcionarios y la cantidad de funcionarios con discapacidad insertadas según la ley 3585/08 (SFP, 2014). 
Para indagar sobre la inserción laboral de las PcD en las instituciones privadas, en relación a la incorporación laboral de las $\mathrm{PcD}$, se incluyó a 5 empresas a participar en la investigación, las mismas fueron seleccionadas según publicación realizada por la Fundación SARAKI por considerarlas inclusivas (Fundación SARAKI, 2013); a las empresas intervinientes se solicitó su cooperación y permiso para publicar sus nombres y los resultados. Fueron incluidos en total 3 empresas de la capital y 2 empresas del interior del país, se concretó la entrevista con los gerentes de las empresas con el respaldo de un cuestionario semiestructurado con preguntas abiertas, que fueron respondidas por los entrevistados.

\section{RESULTADOS Y DISCUSIÓN}

El Paraguay cuenta con una población de 6.818.180 habitantes, de las cuales en edad económicamente activa está constituida por 3.163.241 habitantes (DGEEC, 2014). Para fijar la población con discapacidad económicamente activa en el país se tomó el parámetro del $10 \%$ que establece la Organización Mundial de la Salud (OMS), el cálculo arroja como resultado 316.324 habitantes (OMS, 2009).

Para constituir la cantidad de Personas con Discapacidad (PcD) económicamente activa con posibilidad de trabajar, se encontró que el 5\% de los usuarios con discapacidad se encuentran en condiciones de trabajar, constituyéndose en 15.816 usuarios, de las cuales una 14.000 PcD podrán trabajar en forma dependiente y el resto podrian realizar trabajos en forma independiente (SENADIS, 2012).

En la figura 1 se muestra el panorama general de la población con discapacidad y las posibilidades de acceso en el ámbito laboral. Como puede observarse existe alto porcentaje de $\operatorname{PcD}$ que se encuentran en edad económicamente activa que no pueden acceder a un trabajo, dado a que la proyección estimada actualmente solo llega al $5 \%$ de la población equivalente a 15.816 habitantes de PcD. Esta situación evidencia la necesidad de contar en el país de un Plan de empleabilidad para las PcD con fuerte componente educativo que sea transversal a las políticas implementadas para el sector público y privado.

En lo referente a la población de PcD que demandan empleo, el Departamento de Inserción Laboral de la SENADIS, la encargada de recepcionar y encaminar las solicitudes de inserción laboral a las instituciones públicas y privadas, según su estadística cuenta con 72.450 usuarios registrados, 
distribuidos en 45.950 usuarios definitivos, 17.000 usuarios en prestación de servicios y 9500 usuarios en evaluación (SENADIS, 2012).

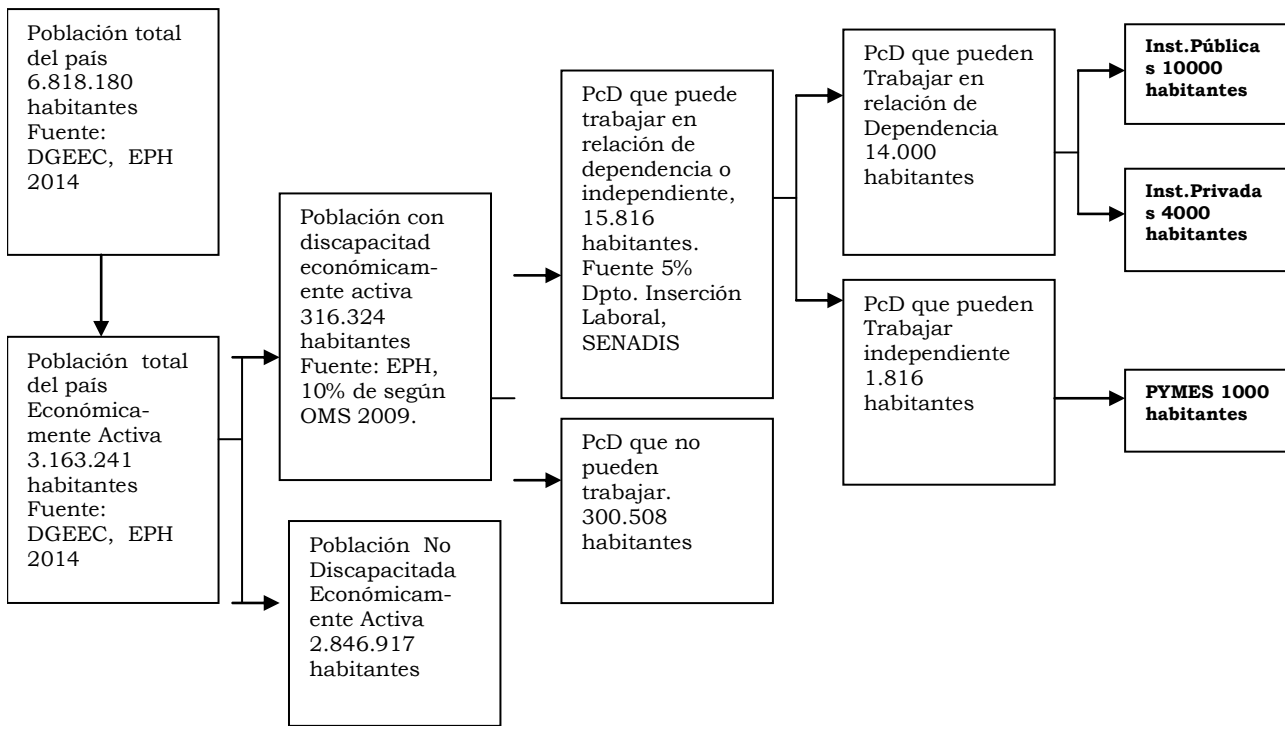

Figura 1. Cuantificación de la población objeto de estudio. Fuente: Elaboración propia, basado en datos de la OMS, 2009; DGEEC, 2009, 2014 y la SENADIS, 2012.

Para tener una característica de la población de PcD que demandan inserción laboral en la SENADIS, fueron analizadas las carpetas de 85 usuarios en los siguientes aspectos: sexo, estado civil, edad, nivel de estudio, formación ocupacional, tipo de discapacidad e inserción laboral.

Los datos de la muestra de la población de PcD que solicita empleo en la SENADIS, en cuando al sexo es uniforme, comprendiendo el $49 \%$ para el sexo masculino y $51 \%$ para el femenino, siendo la diferencia de $2 \%$. La población de PcD distribuida por estado civil indica una tendencia casi igualitaria de PcD que estan casados, siendo $5 \%$ los hombres que estan casados y $6 \%$ de las mujeres que estan casadas.

La distribución de la población con PcD según la edad, se presenta el orden de demanda de trabajo en porcentaje y rango de edad en forma ascendente: de 15- 
25 años en un 25\%, la edad comprendida entre 26-35 años constituye el de mayor demanda consistente en un 39\% y una declinación para los años entre 46-55 años en un $32 \%$ y $4 \%$ para los de 56-60 años de edad. La demanda de trabajo se encuentra marcada en el rango de edad comprendida entre 15 a 45 años, que constituye el rango de edad de las personas económicamente activas.

En cuanto a la formación, la mayor concentración es la formación académica del nivel secundario constituyéndose en un $52 \%$, de los cuales el $73,8 \%$ tiene la secundaria completa y el $21,2 \%$ cuenta con secundaria incompleta. La población que se encuentra a nivel universitaria con $19 \%$, de la cuales el $63,2 \%$ tiene la universitaria completa y el $36,8 \%$ la universitaria incompleta. La población del nivel primario constituye el $29 \%$ de las cuales el $20,8 \%$ tiene la primaria completa y el $79,2 \%$ con primaria incompleta.

La población de PcD distribuida por habilidades muestra que la mayor concentración se encuentra apostada su preparación en el área de la informática. Así, el 35\% tiene conocimiento de tecnología informática, el $28 \%$ cuenta con habilidades manuales agrupadas en peluquería, cocina, corte y confección, manualidades, entre otros, el $15 \%$ con conocimientos administrativos para el trabajo de oficina, el $13 \%$ se encuentra con conocimiento técnico, el $6 \%$ en con conocimiento en área de salud y 3\% está preparado para el arte.

La población de PcD distribuida por Tipo de Discapacidad muestra que la población que más demanda la inserción laboral tiene discapacidad física o motora (68\%), en un $21 \%$ dificultades sensoriales (auditiva, visual, trastornos del lenguaje) y un $10 \%$ discapacidades intelectuales. En cuanto a inserción laboral, de la muestra analizada el 20\% ya están trabajando y el $80 \%$ se encuentran en proceso de inserción. En referencia a la situación de las PcD en actividad laboral en el ámbito público y el cumplimiento de la Ley 3585/08 se consultó en la Secretaría de la Función Pública. Según el registro de la Secretaría, se cuenta con 66 instituciones públicas y entes descentralizados. En total cuentan con 280.246 empleados, de las cuales 1.977 son PcD como funcionarios. De las 66 instituciones públicas y entes descentralizados, se registra que 50 de estas instituciones $(76 \%)$, han iniciado alguna gestión de inserción de las PcD y 16 instituciones (24\%) no registran aún acciones para responder a la Ley 3585/08.

La Ley 3585/08 establece que todos los organismos y entidades del Estado, personas jurídicas de derecho privado con mayoría accionaria del Estado incorporaran y mantendrán dentro de su plantel de personal un porcentaje de PcD 
que no será menor al 5\%. El Estado a través de la Secretaría de la Función Pública orienta la aplicación de la ley de Inserción laboral $\mathrm{PcD}$ en las instituciones públicas, solicitando la competencia de las instituciones que conocen y trabajan con el tema de la discapacidad, de esta convocatoria surge la Mesa interinstitucional para inclusión efectiva de las $\mathrm{PcD}$ en la función pública.

Según la estadística proporcionada por la Secretaría, la población de funcionarios con discapacidad en las instituciones públicas respondiendo a la inserción del 5\% de las PcD a partir de la Ley 3585/08 constituye apenas el 0,7\%, siendo casi nula, quedando un $99,3 \%$ pendiente de ser insertado. Estos datos permite inferir que la situación laboral de las PcD es la desocupación en su gran mayoria, sobre todo porque han tenido escasas oportunidades de educación y de capacitación para el trabajo, salvo algunas excepciones; por ello la aplicación de las leyes que establece la inserción de las $\mathrm{PcD}$ en las instituciones públicas ha contribuido con una inserción considerable en cuanto al acceso a este derecho. En este sentido, la Secretaría manifiesta que tiene previsto insertar en forma gradual en las instituciones públicas aproximadamente $16.000 \mathrm{PcD}$, esta cantidad se aproxima al cálculo de esta investigación de 15.816 PcD que necesitan ser insertadas en el ámbito laboral público o privado.

Por otro lado, las empresas privadas constituyen una fuente importante para la inserción laboral de las $\mathrm{PcD}$, al respecto fueron consultadas 5 empresas privadas (3 de la capital y 2 del interior del país). En la capital, se concretó la entrevista con los gerentes de las empresas Nuestra Señora de la Asunción, Empresa Gráfica Asuncena y Empresa Diesa S.A. Las empresas del Interior, a Visión Banco de la ciudad de San Pedro del Ycuamandiyú y la empresa Petrobras de la ciudad de Horqueta.

La postura de las empresas privadas en relación al acceso al empleo de las PcD en las instituciones privadas, indica que el 100\% de las empresas tiene en su historial alguna forma de relación laboral con la contratación de PcD como empleados, siendo la responsabilidad social y la iniciativa de diferentes organizaciones gubernamentales y no gubernamentales que impulsan el acceso al trabajo como derecho. Por tanto, podemos decir que las mencionadas empresas, se encuentran en una situación de apertura, dispuestos a insertar a las PcD, muestran buena predisposición para introducir las adecuaciones edilicias necesarias y de los puestos de trabajo en forma gradual según las normas de la accesibilidad. Una gran cantidad de las instituciones privadas encuentran insertando bajo la norma de responsabilidad social ya que no se cuenta con una 
ley que los obligue al cumplimiento (Tabla 1).

Tabla 1. Resumen de las entrevistas realizadas a Empresas Privadas.

\begin{tabular}{|c|c|}
\hline Empresa & Resultado de la entrevista \\
\hline $\begin{array}{l}\text { Empresa de } \\
\text { Transporte } \\
\text { Nuestra } \\
\text { Señora de la } \\
\text { Asunción }\end{array}$ & $\begin{array}{l}\text { La inclusión laboral de las PcD en la empresa es una realidad desde el punto de vista de } \\
\text { la responsabilidad social, dando oportunidad a } 8 \text { PcD. Para el mismo se necesitó } \\
\text { introducir cambios graduales en los accesos del edificio, adecuación del lugar de } \\
\text { trabajo, cambios en el plantel de empleados insertando un profesional en el área de } \\
\text { Trabajo Social, que esté trabajando con el asesoramiento del Departamento de Inserción } \\
\text { Laboral del INPRO. Son partidarios de impulsar politicas públicas para fortalecer el } \\
\text { acceso al trabajo de las PcD. El mayor beneficio radica en el cumplimiento con el área } \\
\text { de discapacidad, el cumplimiento con la sociedad, el logro de la igualdad de } \\
\text { oportunidades y el cambio positivo generado dentro de la organización. }\end{array}$ \\
\hline $\begin{array}{l}\text { Gráfica } \\
\text { Asuncena }\end{array}$ & $\begin{array}{l}\text { La empresa inició la inserción laboral con una PcD, a solicitud del Departamento de } \\
\text { Inserción Laboral de INPRO, la empresa accedió gustosa, pues ya estaba sensibilizado a } \\
\text { través de un trabajo de impresión de folletería realizado para la Fundación Saraki. El } \\
\text { directorio se ocupa de ir realizando los ajustes correspondientes para que la empresa } \\
\text { sea accesible, actualmente se recibe asesoramiento del Departamento de Inserción } \\
\text { Laboral de INPRO. Al inicio el directorio tuvo temor con la reacción actitudinal de los } \\
\text { empleados, pero el resultado fue diferente, la PcD que ingresó dio ejemplo de } \\
\text { puntualidad, respeto y deseo de superación, la inserción introdujo cambios positivos en } \\
\text { los empleados de la empresa. }\end{array}$ \\
\hline Diesa S.A. & $\begin{array}{l}\text { La empresa inició la Inserción laboral de las PcD, a partir de los años } 80 \text { como una } \\
\text { politica del directorio, la inserción fue realizándose en forma gradual y hoy dia se } \\
\text { cuenta en número de } 6 \mathrm{PcD} \text {, se cuenta con convenios de pasantia e inserción con varias } \\
\text { instituciones encargadas de las tareas afin al tema. Los empleados y jefes de la } \\
\text { institución se encuentran sensibilizados y con actitud positiva hacia esta politica } \\
\text { empresarial. Las instalaciones nuevas se encuentran adecuadas al acceso y las } \\
\text { instalaciones más viejas se están adecuando en forma gradual. El directorio, se } \\
\text { encuentra apoyando su promulgación, con relación a los incentivos solicita un mejor } \\
\text { estudio y reglamentación y sugiere que apunte a los incentivos fiscales. }\end{array}$ \\
\hline $\begin{array}{l}\text { Visión } \\
\text { Banco }\end{array}$ & $\begin{array}{l}\text { La empresa dentro de su programa de responsabilidad social empresarial tiene } 6 \text { PcD } \\
\text { en todo el país de las cuales } 1 \text { PcD es de esta sucursal (San Pedro del Ycuamandiyú), se } \\
\text { desempeña como auxiliar de servicios. Actualmente, está apoyando la labor realizada } \\
\text { por la Fundación Saraki. En forma conjunta se realiza la selección para ubicar en un } \\
\text { lugar en donde puedan sentirse bien y desempeñarse como persona. Todas las } \\
\text { instalaciones contemplan las normas exigidas para la accesibilidad y fiscalizada por la } \\
\text { Fundación Saraki. Las PcD se encuentran desempeñándose favorablemente, son } \\
\text { responsables a la hora de trabajar, no dan motivo para que exista diferencia. Como } \\
\text { empresa tiene la satisfacción de ser ejemplos dentro los programas de responsabilidad } \\
\text { social e inclusión laboral de las PcD, son bien catalogados en el país y el mundo. }\end{array}$ \\
\hline Petrobras & $\begin{array}{l}\text { Dentro del programa de responsabilidad social tiene firmada convenios de contrato } \\
\text { laboral para PcD con la Fundación Saraki y la Fundación Discar. Tiene incluida a las } \\
\text { PcD, la inserción se realiza en forma creciente. Todo el proceso de educación, } \\
\text { preparación, inserción y seguimiento lo realiza las empresas asociadas al programa. } \\
\text { Todas las áreas de atención al cliente y las del área administrativa son accesibles, } \\
\text { cumpliendo con las reglamentaciones exigidas. La PcD insertadas en esta empresa son } \\
\text { activas, solidarias, cumplidores con su responsabilidad, son ejemplos para los demás } \\
\text { compañeros. Los empresarios manifiestan su apoyo a la ley de inserción laboral, que } \\
\text { beneficiara al país y a las empresas, consideran que con esto se logrará la igualdad, la } \\
\text { integración plena de los cuidadanos y una sociedad más sensibilizada. }\end{array}$ \\
\hline
\end{tabular}

Los desafios políticos destacados por los empresarios son: Fortalecimiento empresarial a través de la inserción laboral de las PcD. La visualización de las PcD, 
sus potencialidades y habilidades para asumir responsabilidades y erradicar la discriminación y los tabúes con relación a las PcD. La sensibilización de la sociedad en la necesidad de trabajo de las PcD. Para el proceso de preparación y capacitación de las PcD, las empresas se encuentran preparándose o solicitando ayuda a instituciones para ese cometido. Las características mencionadas en relación a las $\mathrm{PcD}$ en el sector privado demuestran su grado de responsabilidad, cumplimiento y aprendizaje en el ámbito laboral, generando un ambiente favorable donde no se acentúa las diferencias por el tipo de relacionamiento activo y afectivo que se da con los demás empleados.

La inserción de PcD en las empresas privadas genera beneficios favorables expresados en cumplimiento del deber con la sociedad y el sector de discapacidad, logro de la igualdad de oportunidades, la sensibilización, cambios de actitud, adecuación edilicia de las organizaciones, la mejora de actitud y responsabilidad de los empleados sin discapacidad.

Cabe destacar que en diferentes instituciones públicas y empresas privadas es posible observar hoy en día a personas con alguna discapacidad, cumpliendo labores; situación no visible anteriormente. Existen también numerosas organizaciones de padres, amigos, y de PcD como la Fundación SARAKI, la Asociación de Rehabilitación de Impedidos Físicos del Paraguay (ARIFA), Fundación TELETON, Asociación de Padres y Amigos de personas Excepcionales (APAPEX), Centro de Sordos del Paraguay (CSP), Asociación de Ciegos del Paraguay (ACIP), Centro Ovetense de Ayuda Social al Niño con Impedimentos Físicos (COANIF), Asociación de Padres y Amigos para Personas con Deficiencias Mentales de Alto Paraná (APAMAP) y otros (Fundación SARAKI, 2013).

En este sentido es importante resaltar que distintas organizaciones de la sociedad civil que pugnan en pro de los derechos y dignidad de las PcD han conseguido avances en materia de políticas de inserción laboral a nivel nacional. Entre las experiencias exitosas que contribuyen en la inserción laboral de las PcD podemos mencionar a la Municipalidad de Asunción que ha implementado a partir del año 1993 el "Programa de Inserción Laboral", mediante el cual numerosos jóvenes han podido acceder a un trabajo remunerado. Ha desarrollado programas de prevención de la discapacidad en los barrios ubicados en zonas de riesgo y se han eliminado barreras arquitectónicas (Municipalidad de Asunción, 2015). Por su parte, el Departamento de Talleres de la SENADIS tiene talleres protegidos y de formación para el trabajo dirigido a personas con escaso recurso económico (SENADIS, 2014). 
Con lo mencionado, se puede apreciar que el aporte de las organizaciones civiles organizadas ha sido y es importante en cuanto a las campañas de concienciación y sensibilización desarrolladas con el sector privado, respaldados con componentes educativos que explican la apuesta generada por estas empresas. Sin embargo, las Instituciones que se encargan de la Inserción Laboral de las PcD en el país en las Instituciones privadas han logrado la inserción de un total de $142 \mathrm{PcD}$, equivalente al $1 \%$, siendo esta cantidad muy pequeña en relación a los 15.816 PcD que necesitan ser insertadas.

\section{CONCLUSIONES}

En la identificación de la situación laboral de las PcD en el Paraguay se observa que las leyes del país cuentan con acciones positivas a favor de las $\mathrm{PcD}$, resaltándose en lo laboral, la Ley 3585/08, que obliga la inserción laboral de PcD en las instituciones públicas, la Ley 4962/13 que establece beneficios para los empleadores a los efectos de incentivar la incorporación de PcD en el sector privado. Estas leyes son motivadoras para la población de PcD incentivándolos a seguir luchando por otros logros como la reglamentación y el cumplimiento efectivo de la inserción laboral de las PcD.

El Estado Paraguayo asume el compromiso internacional de la Convención de los Derechos Humanos de las PcD, como efecto positivo genera la Ley 4720/12 que crea la Secretaria Nacional por los Derechos de las Personas con Discapacidad (SANADIS), que eleva de categoria de secretaria al Instituto Nacional de Protección a las Personas Excepcionales (INPRO), este contexto permitirá la formulación de políticas y planes nacionales en materia de la discapacidad; mayor participación de las PcD y las organizaciones que las representen, coordinar las politicas y acciones necesarias para dar cumplimiento a los programas nacionales garantizando la equidad e igualdad de oportunidades y como aporte al cumplimiento de los fines de la SENADIS se diseña del Plan de Empleabilidad para las PcD (PNE) que forma parte de la recomendación de esta investigación.

Según puede observarse en los datos analizados el país cuenta con 316.324 PcD en edad económicamente activa, de las cuales 15.816 PcD están en condiciones de ser insertadas laboralmente, siendo apenas el $1 \%$ de esta población que ya han logrado ser insertada, quedando mucho por hacer en el área de la inserción laboral de las PcD. En cuanto a las características de la PcD que solicitan empleo se constata que la población de PcD que solicitan empleo es uniforme en cuanto al sexo, la edad está comprendida entre 26 y 35 años, respondiendo a la población económicamente activa del país. 
En cuanto al nivel de estudio, la gran mayoría cuentan con la secundaria incompleta, son muy pocos los que obtienen un título universitario; las habilidades están distribuidas en orden de importancia, entre los que tienen preparación en informática, trabajo manual, administrativo, técnico, área de salud y arte. En cuanto al tipo de discapacidad, el mayor porcentaje la constituye la discapacidad fisica, seguida de la sensorial e intelectual.

La empleabilidad de las PcD depende de la concienciación de la sociedad, de la capacidad, preparación de las PcD y de las opciones políticas que emprende el Estado y la sociedad civil hacia el sector. Cabe destacar el entendimiento profesional por parte de las instituciones públicas y privadas de la importancia de vincular a las PcD al empleo desde una perspectiva de derechos. Esta situación garantiza que los derechos de todas las personas sean avaladas por los organismos tanto públicos como privados. Las leyes son claras en cuanto a la inserción laboral en las instituciones públicas, solo hace falta crear los mecanismos para poner a funcionar los planes que hagan posible la ejecución del cumplimiento de las leyes, para ello esta investigación propone un Plan de Empleabilidad para las PcD.

En cuanto al grado de apertura de las Instituciones Privadas, en la incorporación de PcD como empleados, se encuentran varias organizaciones (ONG's, Fundaciones) que pugnan a favor de la inserción de las PcD, trabajando con varias empresas privadas interesadas en incluir entre sus empleados a las PcD. Entrevistando a los responsables de las empresas privadas, respondieron favorablemente a la inclusión laboral de las PcD; expresaron no tener dificultades actitudinales, económicas, arquitectónicas; que no incurririan en grandes inversiones para lograr la adecuación de acceso a sus edificios y en los puestos de trabajo; que las nuevas edificaciones ya cuentan con las exigencias arquitectónicas previstas según las normas de la accesibilidad. Los consultados, se encuentran abiertos a la inserción de las PcD en los puestos de trabajo, se observa que un número de PcD están insertos laboralmente a través de las acciones emprendidas por las organizaciones de y para las $\mathrm{PcD}$, que se insertaron no por exigencia de una ley sino por la responsabilidad social de las empresas.

Las empresas privadas constituyen una fuente importante para la inserción laboral de las PcD, siendo urgente la reglamentación de la Ley de Incentivo Fiscal para las Empresas Privadas que permitirá el ingreso de las $\mathrm{PcD}$ al sector privado por medio una ley que lo ampare.

Los resultados de este estudio sugieren la investigación de otros aspectos relacionados con los Derechos Humanos de las PcD y abordar nuevas aristas de la 
empleabilidad de las PcD. Que el trabajo sea extensivo al Estado, las Organizaciones públicas y privadas, en especial a la SENADIS para que le sirva de material de consulta y referencia para los temas relacionados a la generación de políticas públicas y tareas propias de la Inserción laboral de las PcD.

La SENADIS necesita insertar dentro de su estructura organizativa a la Dirección de Empleabilidad y dentro de esta dirección ejecutarse el Plan de Empleabilidad para las PcD, propuesta presentada como parte de la recomendación de esta investigación. Confiar a la Comisión Asesora de reglamentación de la SENADIS el uso del Plan Nacional de Empleabilidad (PNE) para las $\mathrm{PcD}$, para la organización de las estructuras relacionadas al empleo. Realizar la difusión a nivel nacional del Plan de Empleabilidad para la PcD a fin de que su conocimiento sea público y revisar el PNE dentro de un periodo razonable para introducir mejoras, modificaciones y ajustes según las necesidades emergentes.

\section{Diseño del Plan Nacional de la Empleabilidad (PNE)}

Tras la revisión de los planes de empleabilidad implementados en otros países (España, Chile y Perú) y al realizar un análisis crítico de las leyes que amparan a la discapacidad en el empleo, la situación de las PcD en el país, las acciones de las instituciones públicas y privadas, se procede a elaborar el Diseño de la propuesta del PNE, cuyo resumen se presenta en la tabla 2.

Tabla 2. Estructura del diseño del Plan Nacional de la Empleabilidad (PNE) con áreas operacionales.

\begin{tabular}{|c|c|c|c|c|}
\hline Dirección & $\begin{array}{l}\text { Departa } \\
\text { mento }\end{array}$ & Área & & Actividades \\
\hline \multirow[t]{5}{*}{$\begin{array}{l}\text { Empleabilidad } \\
\text { del PNE }\end{array}$} & $\begin{array}{l}\text { Departam } \\
\text { ento } \\
\text { Difusión }\end{array}$ & & & \\
\hline & $\begin{array}{l}\text { Departam } \\
\text { ento de la } \\
\text { Inserción } \\
\text { Laboral }\end{array}$ & $\begin{array}{l}\text { Área } \\
\text { Inserción }\end{array}$ & $\begin{array}{l}\text { - Convocatoria } \\
\text { - Orientación } \\
\text { - Educación } \\
\text { - Selección }\end{array}$ & $\begin{array}{l}\text { - Capacitación } \\
\text { - Promoción } \\
\text { - Acceso } \\
\text { - Evaluación } \\
\end{array}$ \\
\hline & & $\begin{array}{l}\text { Área } \\
\text { Seguimiento }\end{array}$ & $\begin{array}{l}\text { - Permanencia } \\
\text { - Acceso físico }\end{array}$ & $\begin{array}{l}\text { - Seguimiento Inst. Públicas } \\
\text { - Seguimiento Inst. Privadas }\end{array}$ \\
\hline & & $\begin{array}{l}\text { Área del } \\
\text { Emprendedor }\end{array}$ & $\begin{array}{l}\text { - Convocatoria } \\
\text { - Orientación } \\
\text { - Educación } \\
\text { - Capacitación }\end{array}$ & $\begin{array}{l}\text { - Promoción. } \\
\text { - Acceso } \\
\text { - Evaluación Desempeño } \\
\text { - Seguimiento de permanecía } \\
\text { en el mercado } \\
\end{array}$ \\
\hline & $\begin{array}{l}\text { Departam } \\
\text { ento de } \\
\text { Redes }\end{array}$ & & \multicolumn{2}{|c|}{$\begin{array}{l}\text { - Interinstitucional } \\
\text { - Legal } \\
\text { - Descentralización }\end{array}$} \\
\hline
\end{tabular}


El detalle de la propuesta se encuentra disponible en la biblioteca de la Universidad Autónoma de Asunción en la tesis "Empleabilidad de las Personas con Discapacidad desde el Marco Rector de la Secretaria Nacional por los Derechos Humanos de las Personas con Discapacidad (SENADIS), Paraguay" (Reyes, 2014).

\section{REFERENCIAS}

Arregui, E., y Romero, E. (2010). Mirando a las personas con discapacidad desde una visión de derechos. Madrid: Estudios.

Carrizosa, A. (2010). Iniciativa ciudadana, inserción laboral de las personas con discapacidad. Periódico Digital Iniciativas Ciudadanas, 43, julio, 5-6.

Constitución Nacional. (1992.) Constitución Nacional de la República del Paraguay. Recuperado de: http://www.bacn.gov.py/constitucion-nacional-de-la-republica-del-paraguay.php

DGEEC (Dirección General de Estadísticas, Encuestas y Censos). (2009). Principales indicadores de empleo. Asunción: DGEEC.

DGEEC (Dirección General de Estadísticas, Encuestas y Censos). (2014). Principales indicadores de empleo. Asunción: DGEEC.

Fundación SARAKI. (2013). Empresas que apuestan a la inclusión. Boletín Digital, 34, mayo. 6-7.

Ley 780/79. (1979). Creación del Instituto Nacional de Personas Excepcionales. Asunción: Registro Oficial.

Ley 3585/08. (2008). Que modifica los artículos $1^{\circ}, 4^{\circ}$ y $6^{\circ}$ de la Ley $n^{\circ} 2479 / 04$, que establece la obligatoriedad de la incorporación de personas con discapacidad en las instituciones públicas. Asunción: Registro Oficial.

Ley 4720/12. (2012). Creación de la Secretaria Nacional por los Derechos Humanos de las Personas con Discapacidad. Asunción: Registro Oficial.

Municipalidad de Asunción. (2015). Portal para propiciar programas de capacitación e inserción laboral. Asunción: Municipalidad de Asunción.

OMS, OPS, IMSERSO. (2004). Clasificación Internacional del Funcionamiento de la Discapacidad y la Salud (CIF). Madrid: Grafo.

OMS. (2009). Discapacidad y salud, nota descriptiva $N^{\circ} 352$. Washington: Centro de prensa de la OMS.

OMS. (2012). Rehabilitación basada en la comunidad. Ginebra: OMS.

Reyes, A. (2014). Empleabilidad de las personas con discapacidad desde el marco rector de la Secretaria Nacional por los Derechos Humanos de las Personas con Discapacidad (SENADIS), Paraguay. Asunción: UAA.

SENADIS. (2012). Estadistica del departamento de admisión de la SENADIS. Asunción: SENADIS.

SENADIS. (2014). Aproximación a la realidad de las personas con discapacidad. Asunción: SENADIS.

SFP. (2014). Funcionarios permanentes y funcionarios con discapacidad en las instituciones públicas. Asunción: SFP. 